\title{
Carvedilol alleviates diabetic cardiomyopathy in diabetic rats
}

\author{
WENCHENG ZHENG ${ }^{1}$, DING LI $^{2}$, XIANG GAO $^{3}$, WENQIAN ZHANG ${ }^{4}$ and BARRY O. ROBINSON ${ }^{5}$ \\ ${ }^{1}$ Fourth Department of Cardiology, Tangshan Gongren Hospital, Tangshan, Hebei 063000; \\ ${ }^{2}$ Department of Cardiac Electrophysiology, Peking University People's Hospital, Peking University, Beijing 100044; \\ ${ }^{3}$ First Department of Cardiology and ${ }^{4}$ Department of Neurosurgery, Tangshan Gongren Hospital, Tangshan, \\ Hebei 063000, P.R. China; ${ }^{5}$ Department of Non-Invasive Cardiovascular Services, \\ Brookwood Health Hospital, Birmingham, AL 35211, USA
}

Received June 11, 2018; Accepted September 27, 2018

DOI: $10.3892 /$ etm.2018.6954

\begin{abstract}
Diabetic cardiomyopathy (DCM) is characterized by structural and functional changes in the myocardium. Several studies have revealed that myocardial apoptosis and fibrosis occur during DCM. Studies have also indicated that oxidative stress may be a major factor associated with the development of DCM. Protein kinase C (PKC) $\beta_{2}$ has been demonstrated to be activated in diabetic rats, and overexpression of $\mathrm{PKC} \beta_{2}$ in the myocardium may result in cardiac hypertrophy and fibrosis. The P66 $6^{\text {shc }}$ adaptor protein, which is mediated by PKC $\beta$, serves an important role in apoptosis during oxidative stress. The aim of the present study was to investigate whether the $\mathrm{PKC} \beta_{2} / \mathrm{P} 66^{\text {shc }}$ oxidative stress pathway is associated with DCM, and to investigate the role and mechanisms of carvedilol in preserving cardiac function. Experimental diabetic rat models were induced by streptozotocin treatment accompanied by high energy intake. Carvedilol was orally administrated at a dose of 1 or $10 \mathrm{mg} / \mathrm{kg} / \mathrm{day}$. Cardiac function was evaluated by serum $\mathrm{N}$-terminal pro-B-type natriuretic peptide level and cardiac ultrasound. Myocardial inflammation, oxidative stress, apoptosis and fibrosis were assessed by histopathological and echocardiographic analyses and tests for oxidative markers. Associated proteins and factors were examined by immunohistochemical and western blot analyses. Rats in the diabetes mellitus group exhibited significantly decreased systolic cardiac function along with elevated expression levels of phosphorylated (p)-PKC $\beta_{2}$, phos-P6 $6^{\text {shc }}$, caspase-3, malondialdehyde, collagen type I, tumor necrosis factor- $\alpha$ and interleukin- $1 \beta$, which were accompanied by disorder in metabolic processes. Treatment with carvedilol reversed these changes. Thus, the present results suggest
\end{abstract}

Correspondence to: Dr Ding Li, Department of Cardiac Electrophysiology, Peking University People's Hospital, Peking University, 11 Xizhimen South Street, Xicheng, Beijing 100044, P.R. China

E-mail: lidingpku666@126.com

Key words: carvedilol, apoptosis, fibrosis, diabetic cardiomyopathy, oxidative stress, protein kinase $\mathrm{C} \beta_{2}, \mathrm{P} 66^{\text {shc }}$, signaling pathway that the $\mathrm{PKC} \beta_{2} / \mathrm{P}^{6} 6^{\text {shc }}$ signaling pathway may be associated with diabetic cardiomyopathy; furthermore, carvedilol, as a novel $\beta$-receptor blocker, may protect the myocardium from injury by suppressing the myocardial inflammatory response, fibrosis, P6 $6^{\text {shc }}$-mediated oxidative stress and subsequent apoptosis in myocardial tissue. Consequently, carvedilol may have potential as a therapy for the treatment of DCM.

\section{Introduction}

Diabetic mellitus (DM), a major health problem due to its high prevalence and concomitant risks of cardiovascular disease, has been identified as a major factor associated with cardiac mortality. There is currently rapid growth in the number of diabetic patients worldwide, which will potentially reach 439 million by 2030 (1); clinical, pathological and experimental studies all indicate this level of increase (2,3). Diabetic cardiomyopathy (DCM), as an independent cardiovascular complication of DM, is characterized by myocardial dysfunction in the absence of valvular heart disease, hypertension and coronary heart disease. Previous studies have also revealed that myocardial inflammation, lipid accumulation, oxidative stress, apoptosis and fibrosis are associated with the pathophysiology of DCM $(4,5)$. Although the pathogenesis of DCM is multifactorial, oxidative stress has been recognized as a major activating factor, and it serves a pivotal role in the pathology of DCM (1-8).

Protein kinase $\mathrm{C}(\mathrm{PKC})$ enzymes comprise a family of at least 12 serine/threonine protein kinases, which serve important roles in signal transduction and intracellular crosstalk (9). A number of previous studies have demonstrated the association of overexpression or activation of $\mathrm{PKC} \beta_{2}$ in the development and progression of DCM $(10,11)$. The She adaptor protein family consists of $\mathrm{P} 66^{\text {shc }}, \mathrm{P} 52^{\text {shc }}$ and $\mathrm{P} 46^{\text {shc }}$, but only $\mathrm{P} 6^{\text {shc }}$ has been indicated to serve an important role as a redox enzyme implicated in mitochondrial reactive oxygen species (ROS) generation and the translation of oxidative signals into apoptosis (12). Hyperglycemic and hydrogen peroxide stress may activate the $\mathrm{PKC} \beta_{2}$ isoform to induce phosphorylation of $\mathrm{P}^{6}{ }^{\text {shc }}$ at ser36, which can result in the transfer of phosphorylated (p)-P66 ${ }^{\text {shc }}$ from the cytosol to the inner mitochondrial membrane, where $\mathrm{p}-\mathrm{P} 66^{\mathrm{shc}}$ may amplify oxidative stress and catalyze ROS production via cytochrome oxidation (13-15). 
Consequently, it may be hypothesized that the $\mathrm{PKC} \beta_{2} / \mathrm{P} 66^{\text {shc }}$ signaling pathway is associated with the pathogenesis of DCM.

Carvedilol, as a non-selective third-generation $\beta$-adrenoceptor and selective $\alpha$-adrenoceptor blocker, has been widely used in the treatment of heart failure. In particular, previous studies have demonstrated that carvedilol exerts vasodilatatory, anti-oxidative stress and anti-inflammatory effects (16-18).

In the present study, the aim was to investigate whether the $\mathrm{PKC} \beta_{2} / \mathrm{P}_{6} 6^{\text {shc }}$ oxidative stress-signaling pathway is associated with DCM, and to investigate the role and mechanisms of carvedilol in preserving cardiac function.

\section{Materials and methods}

Animals. A total of 70 male 7 week old Wistar rats weighing 180-200 g were purchased from the Laboratory Animal Center of North China University of Science and Technology (Tangshan, China). Prior to the experiments, all rats were fed on a basal diet (BD) for 1 week. All experimental protocols were approved by the Animal Care and Use Committee of North China University of Science and Technology and in compliance with the Guide for the Care and Use of Laboratory Animals (19).

All rats were housed at $22^{\circ} \mathrm{C}$ under a 12 -h light-dark cycle. Diabetes was induced by feeding animals a high-energy diet (HD) during the entire experimental period. Another group $(n=20)$ of rats fed on BD (75\% corn, $20 \%$ wheat bran, $3 \%$ fish meal, $1.5 \%$ farina and $0.5 \%$ salt) served as a control group. To create the high-energy diet, $20 \%(\mathrm{w} /)$ sucrose and $20 \%(\mathrm{w} /)$ lard were added to the BD. Following 4 weeks, diabetes was induced in rats in the HD group by a single intraperitoneal injection of streptozotocin (STZ; Abcam, Cambridge, UK) at a dose of $45 \mathrm{mg} / \mathrm{kg}$ dissolved in $100 \mathrm{mM}$ citrate buffer (pH 4.5), whereas the control group rats were administered an equivalent volume of citrate buffer. Blood glucose levels were examined 1 week following STZ injection using a hand-held glucometer (Roche Diagnostics GmbH, Mannheim, Germany) by tail vein puncture blood sampling. Rats exhibiting a blood glucose value $\geq 16.7 \mathrm{mmol} / 1$ were used for the study $(n=45)$. The diabetic rat group (DM, $n=15)$ and the other 30 diabetic rats were treated with carvedilol [low dosage $(n=15)$, $1 \mathrm{mg} / \mathrm{kg} / \mathrm{d}$ (CarL); high dosage $(\mathrm{n}=15), 10 \mathrm{mg} / \mathrm{kg} / \mathrm{d}(\mathrm{CarH}) ;$ Sigma-Aldrich; Merck KGaA, Darmstadt, Germany] or vehicle (the control group received a basal diet without any drugs at this time) for 20 weeks. All rats were provided with water and food ad libitum.

Measurement of left ventricular function. Trans-thoracic echocardiographic analysis was performed using a Vevo770 imaging system (VisualSonics, Inc., Toronto, ON, Canada) equipped with a high-frequency transducer (frequency band, $12 \mathrm{MHz}$ ). Images were obtained from rats anesthetized with pentobarbital sodium $(1.5 \% ; 30 \mathrm{mg} / \mathrm{kg}$; Nanjing Jiancheng Bioengineering Institute, Nanjing, China). Left ventricular end-diastolic diameter (LVEDd), left ventricular end-systolic diameter (LVEDs) and left ventricular ejection fraction (LVEF) were measured to evaluate the function of the heart. Mean measurements were calculated for five consecutive cardiac cycles and repeated three times. Blood N-terminal pro-B-type natriuretic peptide (NT-proBNP) levels were determined with an auto-biochemical analysis system (Roche Cobas ${ }^{\circledR} \mathrm{C} 311$; Roche Diagnostics, Indianapolis, IN, USA).

Measurement of biochemical factors and heart-to-body weight ratio. Blood glucose and total cholesterol were determined with the auto-biochemical analysis system (Roche Cobas ${ }^{\circledR}$ C311). Following analysis, rats were sacrificed and decapitated, and the heart was immediately removed from each rat to determine heart-to-body weight ratio (HW/BW\%).

Electron microscopy detection. Tissue $\left(\sim 1 \mathrm{~mm}^{3}\right)$ was obtained from the left ventricle and fixed $4^{\circ} \mathrm{C}$ in $2.5 \%$ glutaraldehyde for $2 \mathrm{~h}$, then prepared by the steps described previously (20). The ultrastructural changes in the heart tissue were observed by transmission electron microscopy (FEI Tecnai $\mathrm{G}^{2} 12$ ).

Measurement of myocardium cell size. The left ventricular tissue sections were embedded in paraffin and stained with hematoxylin and eosin (H\&E) as described by Frustaci (21), and were then used for the measurement of myocardium cell size. The short-axis diameter of cardiac myocytes was measured for 10 myocytes selected per field at magnification, x400 via light microscopy. Mean values were obtained from the data on each set of 10 myocytes.

Analysis of inflammatory cytokines in serum. Following the echocardiography measurements, blood samples were collected from the abdominal artery and serum was separated immediately using centrifugation at a speed of $3,000 \mathrm{x} \mathrm{g}$ at $4^{\circ} \mathrm{C}$ for $5 \mathrm{~min}$. The serum levels of tumor necrosis factor (TNF)- $\alpha$ (cat. no. H052) and interleukin (IL)-1 $\beta$ (cat. no. H002) were measured with ELISA kits (Nanjing Jiancheng Bioengineering Institute, Nanjing, China) according to the manufacturer's instructions.

Catalase (CAT), superoxide dismutase (SOD) and malondialdehyde (MDA) activity assays. The CAT (cat. no. A007), SOD (cat. no. A007) and MDA (cat. no. A003) activities in heart tissue were measured via colorimetric analysis using a spectrophotometer with the corresponding detection kits (Nanjing Jiancheng Bioengineering Institute) according to the manufacturer's protocols.

Detection of myocardium fibrosis. The cardiac tissue in paraffin-embedded sections was stained with Masson's trichrome stain. In brief, the paraffin sections $(4 \mu \mathrm{m})$ were dewaxed and rehydrated through gradient alcohol into water. The sections were then washed with tap water and then distilled water, and Regaud's hematoxylin was then used to dye nuclei for 5-10 min at room temperature. The sections were washed with distilled water, then treated with Masson's stain for 5-10 min at room temperature. Following staining, the sections were dipped in $2 \%$ glacial acetic acid solution, then treated with $9.1 \%$ phosphomolybdate solution for differentiation for 3-5 min at room temperature. Following a further $5 \mathrm{~min}$ and without water washing, the sections were directly stained with aniline blue at room temperature, then dipped again in $0.2 \%$ glacial acetic acid solution, followed by dehydration with 95\% and absolute alcohol, xylene clearing and neutral gum 
Table I. Metabolic characteristics of experimental animals.

\begin{tabular}{lccccc}
\hline Group & Glucose $(\mathrm{mmol} / \mathrm{l})$ & $\mathrm{TC}(\mathrm{mmol} / \mathrm{l})$ & $\mathrm{TG}(\mathrm{mmol} / \mathrm{l})$ & $\mathrm{BW}(\mathrm{g})$ & $\mathrm{HW} / \mathrm{BW}(\mathrm{mg} / \mathrm{g})$ \\
\hline NC & $5.30 \pm 1.20$ & $1.35 \pm 0.62$ & $0.70 \pm 0.16$ & $530 \pm 48$ & $2.66 \pm 1.13$ \\
DM & $21.50 \pm 7.10^{\mathrm{a}}$ & $2.76 \pm 1.32^{\mathrm{a}}$ & $7.18 \pm 2.21^{\mathrm{a}}$ & $256 \pm 59^{\mathrm{a}}$ & $4.15 \pm 0.78^{\mathrm{a}}$ \\
DM+CarL & $20.90 \pm 4.30^{\mathrm{a}}$ & $2.73 \pm 0.41^{\mathrm{a}}$ & $7.11 \pm 3.19^{\mathrm{a}}$ & $325 \pm 45^{\mathrm{a}, \mathrm{b}}$ & $3.11 \pm 0.35^{\mathrm{a}, \mathrm{b}}$ \\
DM+CarH & $17.60 \pm 6.50^{\mathrm{a}}$ & $2.69 \pm 0.75^{\mathrm{a}}$ & $7.15 \pm 2.72^{\mathrm{a}}$ & $398 \pm 67^{\mathrm{a}-\mathrm{c}}$ & $3.07 \pm 0.42^{\mathrm{a}-\mathrm{c}}$ \\
F-value & 20.221 & 11.437 & 18.490 & 44.662 & 7.426 \\
\hline
\end{tabular}

${ }^{\mathrm{a}} \mathrm{P}<0.05$ vs. $\mathrm{NC}$; ${ }^{\mathrm{b}} \mathrm{P}<0.05$ vs. $\mathrm{DM} ;{ }^{\mathrm{c}} \mathrm{P}<0.05$ vs. $\mathrm{DM}+\mathrm{CarL}$. TC, total cholesterol; TG, Triglyceride; BW, body weight; HW, heart weight; NC, normal control; DM, diabetic mellitus; CarL, carvedilol low dosage; CarH, carvedilol high dosage.

Table II. Analysis of cardiac function in experimental animals.

\begin{tabular}{lcccc}
\hline Group & LVEDs $(\mathrm{mm})$ & LVEDd $(\mathrm{mm})$ & LVEF (\%) & NT-proBNP (ng/ml) \\
\hline NC & $1.23 \pm 0.23$ & $2.83 \pm 0.04$ & $81.2 \pm 1.8$ & $0.259 \pm 0.061$ \\
DM & $2.75 \pm 0.72^{\mathrm{a}}$ & $3.77 \pm 0.27^{\mathrm{a}}$ & $51.7 \pm 3.3^{\mathrm{a}}$ & $1.385 \pm 0.014^{\mathrm{a}}$ \\
DM+CarL & $1.87 \pm 0.41^{\mathrm{b}}$ & $3.11 \pm 0.15^{\mathrm{b}}$ & $62.5 \pm 4.1^{\mathrm{b}}$ & $0.973 \pm 0.027^{\mathrm{b}}$ \\
DM+CarH & $1.42 \pm 0.38^{\mathrm{b}, \mathrm{c}}$ & $2.73 \pm 0.10^{\mathrm{b}, \mathrm{c}}$ & $75.6 \pm 4.8^{\mathrm{b}, \mathrm{c}}$ & $0.511 \pm 0.032^{\mathrm{b}, \mathrm{c}}$ \\
F-value & 20.752 & 14.062 & 18.811 & 70.841 \\
\hline
\end{tabular}

${ }^{\mathrm{a}} \mathrm{P}<0.05$ vs. NC; ${ }^{\mathrm{b}} \mathrm{P}<0.05$ vs. DM; ${ }^{\mathrm{c}} \mathrm{P}<0.05$ vs. DM+CarL. LVEDs, left ventricular end-systolic diameter; LVEDd, left ventricular end-diastolic diameter; LVEF, left ventricular ejection fraction; NT-proBNP, N-terminal pronatriuretic peptide; NC, normal control; DM, diabetic mellitus; CarL, carvedilol low dosage; CarH, carvedilol high dosage.

Table III. Levels of myocardial inflammatory factors in experimental animals.

\begin{tabular}{lcc}
\hline Group & TNF- $\alpha(\mathrm{ng} / \mathrm{l})$ & $\mathrm{IL}-1 \beta(\mathrm{ng} / \mathrm{l})$ \\
\hline NC & $121.78 \pm 14.50$ & $11.82 \pm 2.18$ \\
DM & $294.38 \pm 56.98^{\mathrm{a}}$ & $26.07 \pm 7.94^{\mathrm{a}}$ \\
DM+CarL & $239.75 \pm 44.78^{\mathrm{b}}$ & $21.53 \pm 0.81^{\mathrm{b}}$ \\
DM+CarH & $208.64 \pm 35.25^{\mathrm{b}, \mathrm{c}}$ & $16.82 \pm 0.73^{\mathrm{b}, \mathrm{c}}$ \\
F-value & 31.102 & 14.335 \\
\hline
\end{tabular}

${ }^{\mathrm{a}} \mathrm{P}<0.05$ vs. $\mathrm{NC} ;{ }^{\mathrm{b}} \mathrm{P}<0.05$ vs. $\mathrm{DM} ;{ }^{\mathrm{c}} \mathrm{P}<0.05$ vs. $\mathrm{DM}+\mathrm{CarL}$. TNF, tumor necrosis factor; IL, interleukin; NC, normal control; DM, diabetic mellitus; CarL, carvedilol low dosage; $\mathrm{CarH}$, carvedilol high dosage.

sealing. Positive staining with Masson's trichrome (fibrotic area) was observed using a light microscope at a magnification of x200, and quantified with a color image analyzer (Leica Microsystems, Ltd., Milton Keynes, UK). The ratio of fibrotic to total area was calculated to determine the extent of myocardial fibrosis.

Immunohistochemistry. Immunohistochemical analysis was performed as described previously (22), using antibodies against caspase-3 at a dilution of 1:50 (cat. no. ab13847; Abcam). The staining for caspase-3 was quantified using Image-Pro plus 6 software (Media Cybernetics, Inc., Rockville, MD, USA).
Table IV. Oxidative stress parameters of experimental animals.

\begin{tabular}{lccc}
\hline Group & $\begin{array}{c}\text { MDA (nmol/g } \\
\text { protein) }\end{array}$ & $\begin{array}{c}\text { SOD (U/g } \\
\text { protein) }\end{array}$ & $\begin{array}{c}\text { CAT(U/g } \\
\text { protein) }\end{array}$ \\
\hline NC & $6.73 \pm 1.21$ & $0.41 \pm 0.05$ & $0.38 \pm 0.03$ \\
DM & $15.89 \pm 2.93^{\mathrm{a}}$ & $0.21 \pm 0.03^{\mathrm{a}}$ & $0.17 \pm 0.04^{\mathrm{a}}$ \\
DM+CarL & $12.24 \pm 1.57^{\mathrm{b}}$ & $0.31 \pm 0.06^{\mathrm{b}}$ & $0.29 \pm 0.05^{\mathrm{b}}$ \\
DM+CarH & $8.62 \pm 0.99^{\mathrm{b}, \mathrm{c}}$ & $0.22 \pm 0.05^{\mathrm{b}, \mathrm{c}}$ & $0.21 \pm 0.02^{\mathrm{b}, \mathrm{c}}$ \\
F-value & 48.723 & 37.221 & 33.772 \\
\hline
\end{tabular}

${ }^{\mathrm{a}} \mathrm{P}<0.05$ vs. $\mathrm{NC} ;{ }^{\mathrm{b}} \mathrm{P}<0.05$ vs. $\mathrm{DM} ;{ }^{\mathrm{c}} \mathrm{P}<0.05$ vs. $\mathrm{DM}+\mathrm{CarL} . \mathrm{MDA}$, malondialdehyde; SOD, superoxide dismutase; CAT, catalase; NC, normal control; DM, diabetic mellitus; CarL, carvedilol low dosage; CarH, carvedilol high dosage.

Western blot analysis. The left ventricle tissues were lysed in radioimmunoprecipitations assay buffer (20 mM Tris, $\mathrm{pH} 7.5$; 150 mM NaCl; 1 mM EDTA; 1 mM EGTA; 1\% TritonX-100; $1 \mathrm{mM} \mathrm{Na} \mathrm{VO}_{4} ; 1 \mathrm{mg} / \mathrm{ml}$ aprotinin, leupeptin and pepstatin; and $1 \mathrm{mM}$ phenylmethylsulfonyl fluoride) and then centrifuged at $10,000 \mathrm{x}$ g for $15 \mathrm{~min}$ at $4^{\circ} \mathrm{C}$. The bicinchoninic acid protein assay (Beyotime Institute of Biotechnology, Haimen, China) was used to examine the protein concentration. Equal quantities of protein $(20 \mu \mathrm{g} /$ lane $)$ were separated using $13 \%$ SDS-PAGE and electro-transferred onto polyvinylidene difluoride membranes (Roche Diagnostics, Indianapolis, IN, USA). The membranes were blocked with $5 \%$ non-fat milk at room temperature for $1 \mathrm{~h}$ and then incubated with 
primary antibodies against the following proteins: $\mathrm{PKC} \beta_{1}$ (cat. no. sc-8049; Santa Cruz Biotechnology, Inc., Dallas, TX, USA), p-PKC $\beta_{1}$ (cat. no. ab75657; Abcam), PKC $\beta_{2}$ (cat. no. sc-13149), p-PKC $\beta_{2}$ (cat. no. sc-365463), $\mathrm{P} 66^{\text {shc }}$ (cat. no. sc-967), p-P66 ${ }^{\text {shc }}$ (cat. no. sc-81520), caspase-3, collagen I (cat. no. sc-293182) and $\beta$-actin (cat. no. sc-47778) at a dilution of $1: 1,000$ at $4^{\circ} \mathrm{C}$ overnight. Following primary incubation, the membranes were incubated with peroxidase-labeled affinity-purified anti-rabbit/mouse $\operatorname{IgG}(\mathrm{H}+\mathrm{L})$ secondary antibodies (cat. no. 074-1506/074-1806; Kirkegaard \& Perry Laboratories, Inc., Gaithersburg, MD, USA; 1:5,000) for $1 \mathrm{~h}$ at $37^{\circ} \mathrm{C}$. Blots were developed with an enhanced chemiluminescence detection kit (Pierce; Thermo Fisher Scientific, Inc., Waltham, MA, USA). Band intensities were quantified with a densitometer analysis system using Image $\mathrm{Lab}^{\mathrm{TM}}$ software version 5.11 (Bio-Rad Laboratories, Inc., Hercules, CA, USA).

Statistical analysis. The statistical analyses were performed using the SPSS software package, version 18.0 (SPSS, Inc., Chicago, IL, USA); data were presented as the mean \pm standard deviation. Comparisons of the data were performed using one-way analysis of variance followed by a post-hoc Bonferroni test. $\mathrm{P}<0.05$ was considered to indicate a statistically significant difference.

\section{Results}

Animal characteristics. The metabolic characteristics of the rats used in the present study are provided in Table I. In the DM group, there were significantly higher blood glucose and cholesterol levels compared with in the control group $(\mathrm{P}<0.05)$, but there were no significant differences between the treated and untreated diabetic rats $(\mathrm{P}>0.05)$. HW/BW ratio was used to reflect the size of the heart. In the DM group, rats exhibited significantly lower body weight and a higher HW/BW ratio than those in the control group $(\mathrm{P}<0.05)$. Compared with the $\mathrm{DM}$ group, both the DM+CarL and DM+CarH groups exhibited significantly greater body weight and lower $\mathrm{HW} / \mathrm{BW}$ ratios $(\mathrm{P}<0.05)$.

Carvedilol attenuates left ventricular dysfunction in DCM rats. Echocardiographic parameters and measured NT-proBNP levels are presented in Table II. The results indicated increases in LVEDs, LVEDd and NT-proBNP, and a decrease in EF\% in the DM group compared with the control group $(\mathrm{P}<0.05)$. The $\mathrm{DM}+\mathrm{CarL}$ and $\mathrm{DM}+\mathrm{CarH}$ groups exhibited a decrease in LVEDs, LVEDd and NT-proBNP, and an increase in EF\% when compared with the DM group $(\mathrm{P}<0.05)$. In turn, compared with the DM+CarL group, the DM+CarH group exhibited lower LVEDs, LVEDd and NT-proBNP, and higher EF\% $(\mathrm{P}<0.05)$. Collectively, these changes demonstrated that the diabetic rats developed cardiac dysfunction, and that carvedilol could attenuate DM-induced left ventricular dysfunction in rats; furthermore, CarH appeared to have a more marked effect than CarL.

Carvedilol alleviates myocardium cell hypertrophy and ultrastructural changes. The myocardial structure was detected by $H \& E$ staining and transmission electron microscopy, as presented in Fig. 1A and B, respectively. As demonstrated by transmission electron microscopy, in the control group, typical symmetric myofibrils comprised of $\mathrm{Z}$ lines with sarcomeres exhibited an organized arrangement. Additionally, packed mitochondria adjacent to the fibers were evident. However, in the DM group rats, swollen mitochondria and an increased level of glycogen lysis were observed. Myofibrils appeared destroyed, resulting in a reduction in sarcomere units, and vacuolization was observed in the perinuclear space. Carvedilol treatment attenuated these alterations in the mitochondria, myofilaments, nuclei and $\mathrm{Z}$ lines, as well as glycogen lysis. The diameter of cardiomyocytes was significantly increased in the DM group compared with in the control group $(\mathrm{P}<0.05)$. In turn, the low and high ( 1 or $10 \mathrm{mg} / \mathrm{kg}$ ) doses of carvedilol alleviated the diabetes-induced cardiomyocyte hypertrophy in DM rats $(\mathrm{P}<0.05$; Fig. $1 \mathrm{C})$.

Carvedilol inhibits myocardial inflammation and oxidative stress. The inflammatory factors TNF- $\alpha$ and IL-1 $\beta$ were elevated in the myocardium of the DM group compared with the control group $(\mathrm{P}<0.05)$; whereas, decreased TNF- $\alpha$ and IL-1 $\beta$ levels were detected in the carvedilol-treated groups compared with the DM group (Fig. 1D; Table III). CAT, SOD and MDA are indicators of oxidative stress. As presented in Fig. 1E and Table IV, compared with the control group, there was an increased level of MDA activity and decreased levels of SOD and CAT activities in the DM group (all $\mathrm{P}<0.05$ ). Carvedilol treatment of diabetic rats significantly inhibited MDA activity and upregulated the activity of CAT and SOD (all $\mathrm{P}<0.05$ vs. DM group).

Carvedilol attenuates cardiomyocyte apoptosis. The expression of proapoptotic protein caspase-3 was assessed by immunohistochemistry and western blotting, as depicted in Fig. 2. Enhanced expression of caspase-3 was identified in the DM group compared with that in the control group. Notably, the immunohistochemical staining revealed that carvedilol treatment downregulated the expression of caspase-3, which was further demonstrated by the western blot analysis.

Carvedilol prevents myocardial fibrosis. As presented in Fig. 3A, positive staining with Masson's trichrome revealed apparent fibrosis in the DM group, with a diminished and disorganized collagen network structure in the myocardium, as well as the interstitial and perivascular areas. However, following treatment with carvedilol, it was observed that the dose of either 1 or $10 \mathrm{mg} / \mathrm{kg}$ was equally effective in markedly alleviating the fibrotic changes in the heart. As depicted in Fig. 3B, collagen volume fraction (CVF) was analyzed using the Image-Pro-Plus system (with CVF defined as the ratio of the positive staining area to the total myocardium area on visual inspection). Collagen type I protein is an important indicator of myocardial fibrosis. Western blot analysis of collagen I is presented in Fig. 3C. In the DM group, there was an increase of collagen I compared with the control group. Meanwhile, the diabetic rats treated with carvedilol exhibited a significantly reduced level of collagen I ( $\mathrm{P}<0.05$ vs. DM group).

Carvedilol suppresses the $P K C \beta_{2} / P 66^{\text {shc }}$ signaling pathway. The results of western blotting demonstrated that $\mathrm{p}-\mathrm{PKC} \beta_{2}$ and $\mathrm{p}-\mathrm{P} 66^{\text {shc }}$ were upregulated in the DM group (both 
A

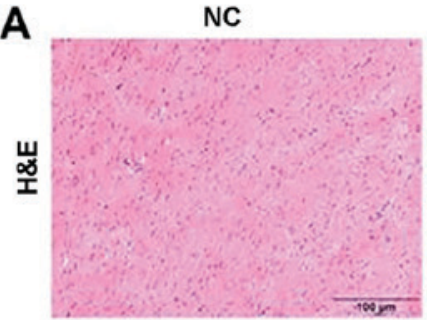

B

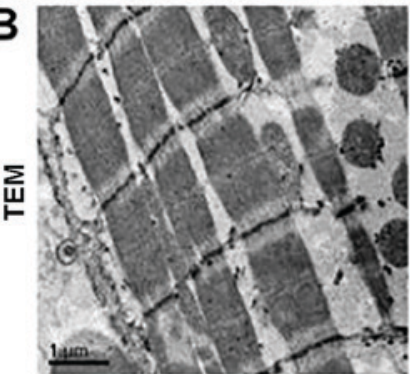

DM
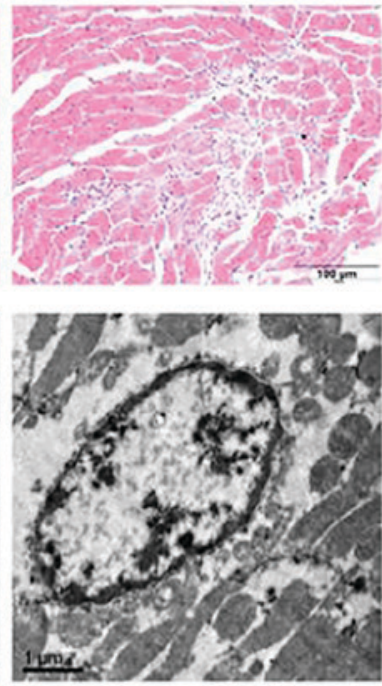

$\mathrm{DM}+\mathrm{CarL}$
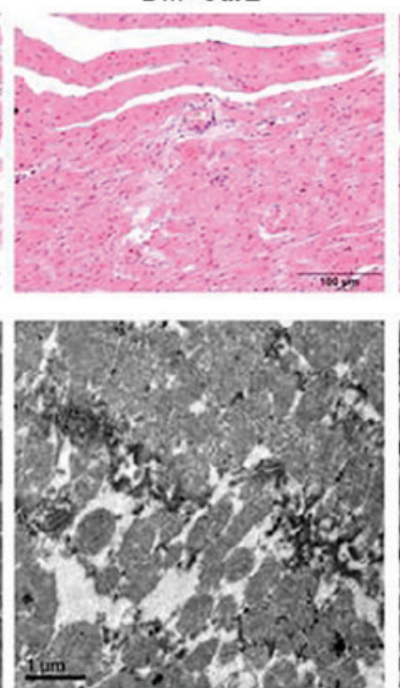
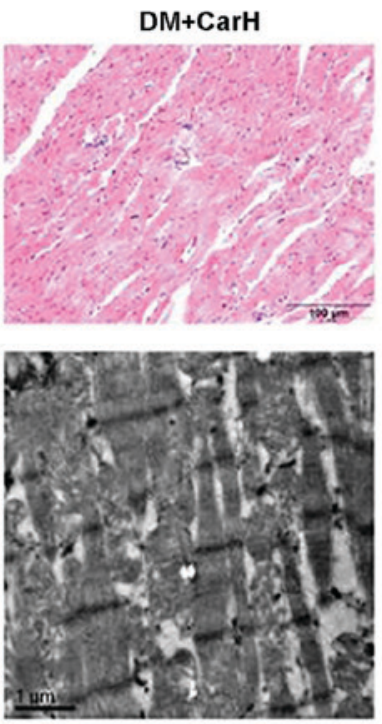

C

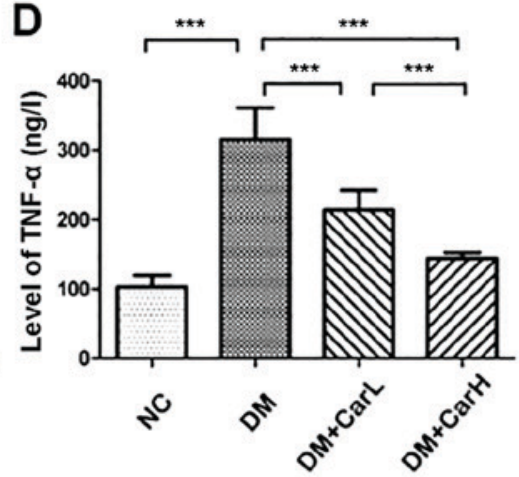

One-way ANOVA ( $F=114.202, n=6)$

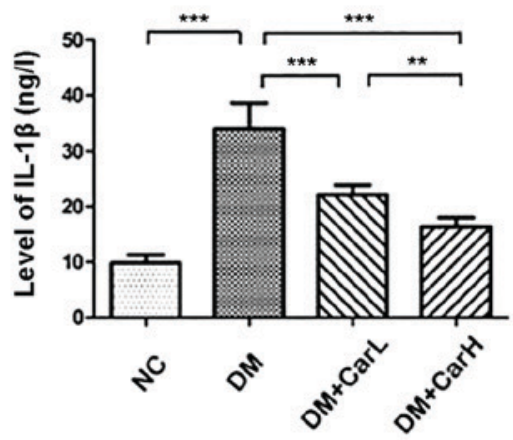

One-way ANOVA $(F=82.711, n=6)$

E

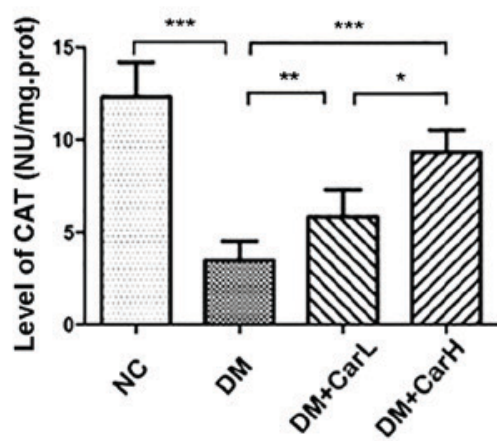

One-way ANOVA $(F=44.146, n=6)$

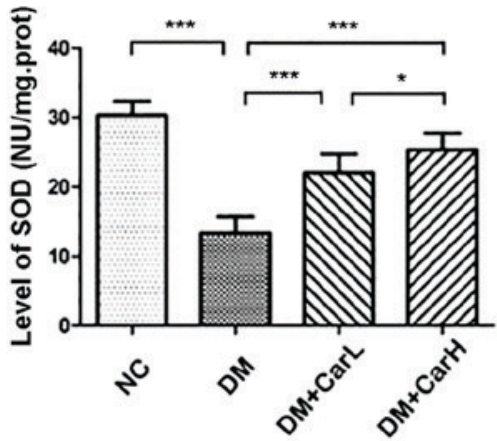

One-way ANOVA ( $F=44.146, n=6)$

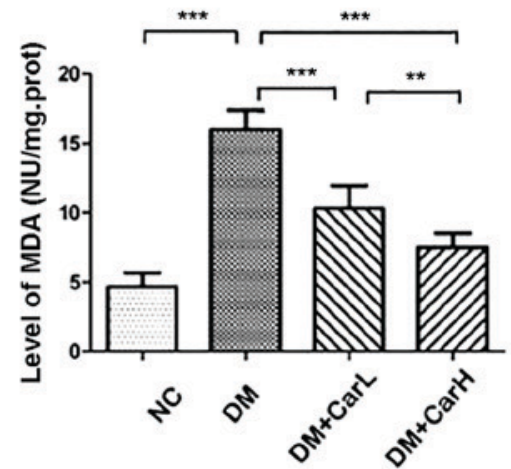

One-way ANOVA $(F=82.236, n=6)$

Figure 1. Carvedilol alleviated myocardium cell size and ultrastructural changes, and inhibited oxidative and inflammatory reaction. (A) H\&E staining of myocardial tissue (magnification, $\mathrm{x} 400 ; \mathrm{n}=6 / \mathrm{group}$ ). (B) Representative TEM graphs of left ventricular apex ( $\mathrm{n}=5 / \mathrm{group}$ ). Swollen mitochondria and disorganized myofibrils are observed in the DM group. (C) Representative diameter of cardiomyocytes. (D) TNF- $\alpha$ and IL-1 $\beta$ indicate inflammatory index ( $\mathrm{n}=6 /$ group). (E) Analysis of variance results. ${ }^{*} \mathrm{P}<0.05,{ }^{* *} \mathrm{P}<0.01$ and ${ }^{* * * *} \mathrm{P}<0.01$. CAT, catalase; SOD, superoxide dismutase; MDA, malondialdehyde.

$\mathrm{P}<0.05$ vs. control group). No marked differences were observed in the levels of $\mathrm{p}-\mathrm{PKC} \beta_{1}$ between the four groups. By contrast, 1 or $10 \mathrm{mg} / \mathrm{kg}$ carvedilol induced a significant decrease in the phosphorylation of $\mathrm{PKC} \beta_{2}$ and $\mathrm{P} 66^{\text {shc }}$ in the myocardium $(\mathrm{P}<0.05$; Fig. 4). Therefore, it was demonstrated that carvedilol inhibited $\mathrm{PKC} \beta_{2}$ activation, and thus $\mathrm{PKC} \beta_{2}$-mediated $\mathrm{P} 66^{\text {shc }}$ activation, in the myocardium of DM-induced rats. This indicated that the $\mathrm{PKC} \beta_{2} / \mathrm{P} 66^{\text {shc }}$ signaling pathway was associated with DCM in the present in vivo model.

\section{Discussion}

Results of the present study suggested that the PKC $\beta_{2} / \mathrm{P} 66^{\text {shc }}$ mitochondrial oxidative stress signaling pathway may be associated with the development of DCM. Activated PKC $\beta_{2}$ has been indicated to serve a crucial role in the pathogenesis of DCM (23). Carvedilol, a novel third-generation non-selective $\beta$-blocker with $\alpha$-receptor blockade activity, does not exhibit side-effects on glucose or lipid metabolism, which is 
A

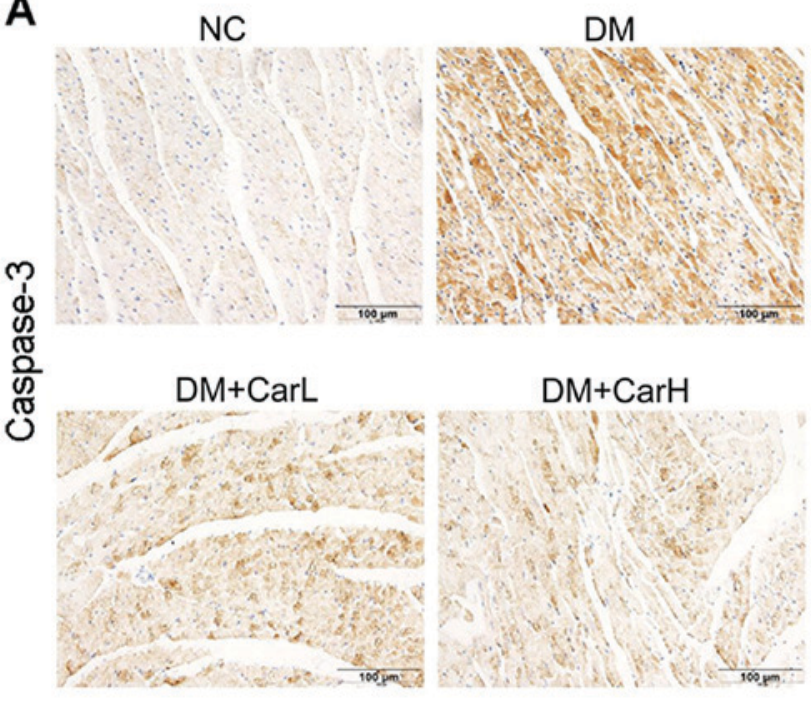

B
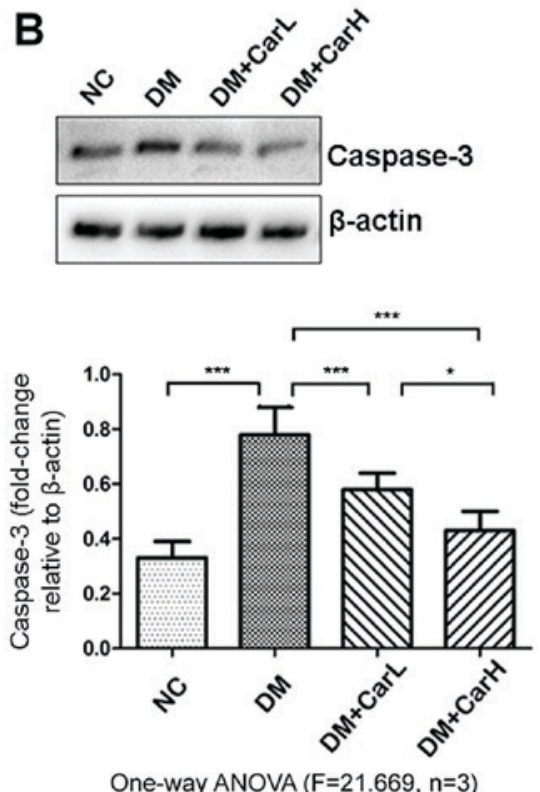

Figure 2. Carvedilol attenuated cardiomyocyte apoptosis. (A) Representative images of immunohistochemical staining of caspase-3 expression, (n=3/group). (B) Western blot analysis of caspase-3 expression ( $\mathrm{n}=3 /$ group). " $\mathrm{P}<0.05$ and $^{* * * *} \mathrm{P}<0.01$. NC, normal control; DM, diabetes mellitus; CarL, carvedilol low dosage; CarH, carvedilol high dosage; ANOVA, analysis of variance.

A

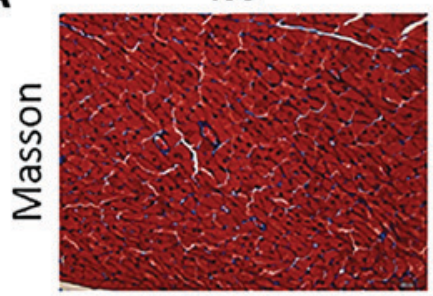

B

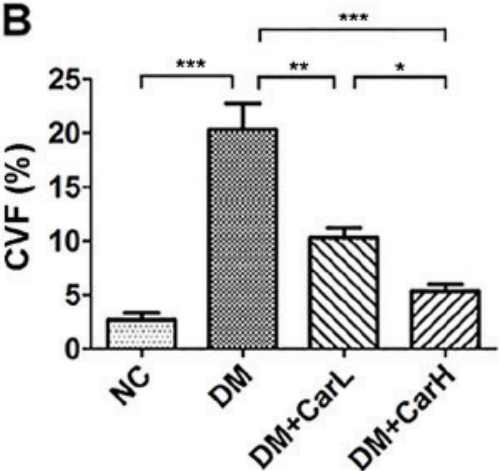

One-way ANOVA ( $F=32.597, n=3)$
DM

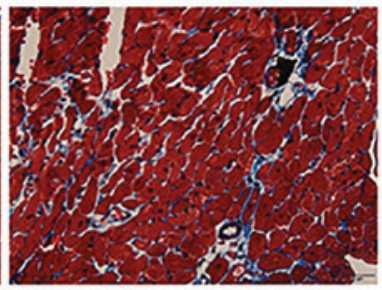

DM+CarL

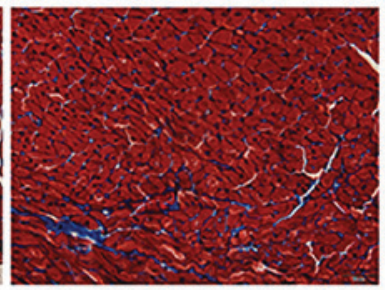

$\mathrm{DM}+\mathrm{CarH}$

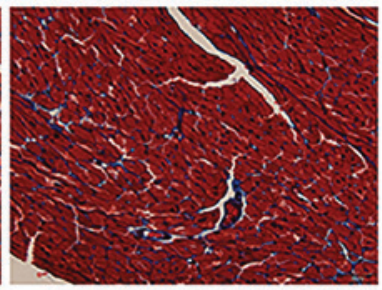

C

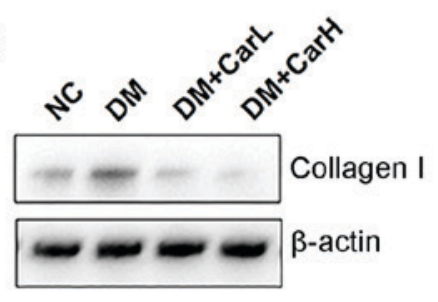

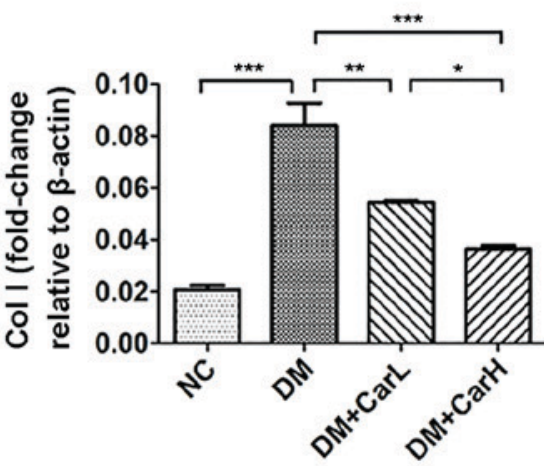

One-way ANOVA $(F=37.208, n=3)$

Figure 3. Carvedilol prevented myocardial fibrosis. (A) Representative images of myocardium tissue sections stained with Masson's trichrome (magnification, $x 400 ; n=3 /$ group). Myocardium stained blue indicates myocardial fibrosis. (B) Representative CVF. (C) Representative Col I protein expression in myocardial tissue ( $\mathrm{n}=3 /$ group). ${ }^{*} \mathrm{P}<0.05,{ }^{* *} \mathrm{P}<0.01$ and ${ }^{* * *} \mathrm{P}<0.01$. CVF, collagen volume fraction; Col I, collagen type I; NC, normal control; DM, diabetes mellitus; CarL, carvedilol low dosage; CarH, carvedilol high dosage; ANOVA, analysis of variance.

contrasting to the first and second generation $\beta$-blockers (24). Previous studies have demonstrated that carvedilol exerts marked improvements in cardiac performance and reduces mortality in humans $(25,26)$. In recent years, there has been increasing interest in the application of carvedilol for the treatment of diabetes-associated complications.

DCM has been defined as left ventricular systolic and diastolic dysfunction in the absence of coronary heart disease, hypertension and valvular heart disease (27), and occurs in both humans and animals. In the present study, a DCM rat model was successfully established, which was characterized by severe disorder of metabolism, cardiomyocyte hypertrophy, fibrosis, cardiac dysfunction, excessive oxidative stress and subsequent inflammation and apoptosis. These characteristics are consistent with a previous study (10). Furthermore, it was demonstrated that long-term carvedilol administration 

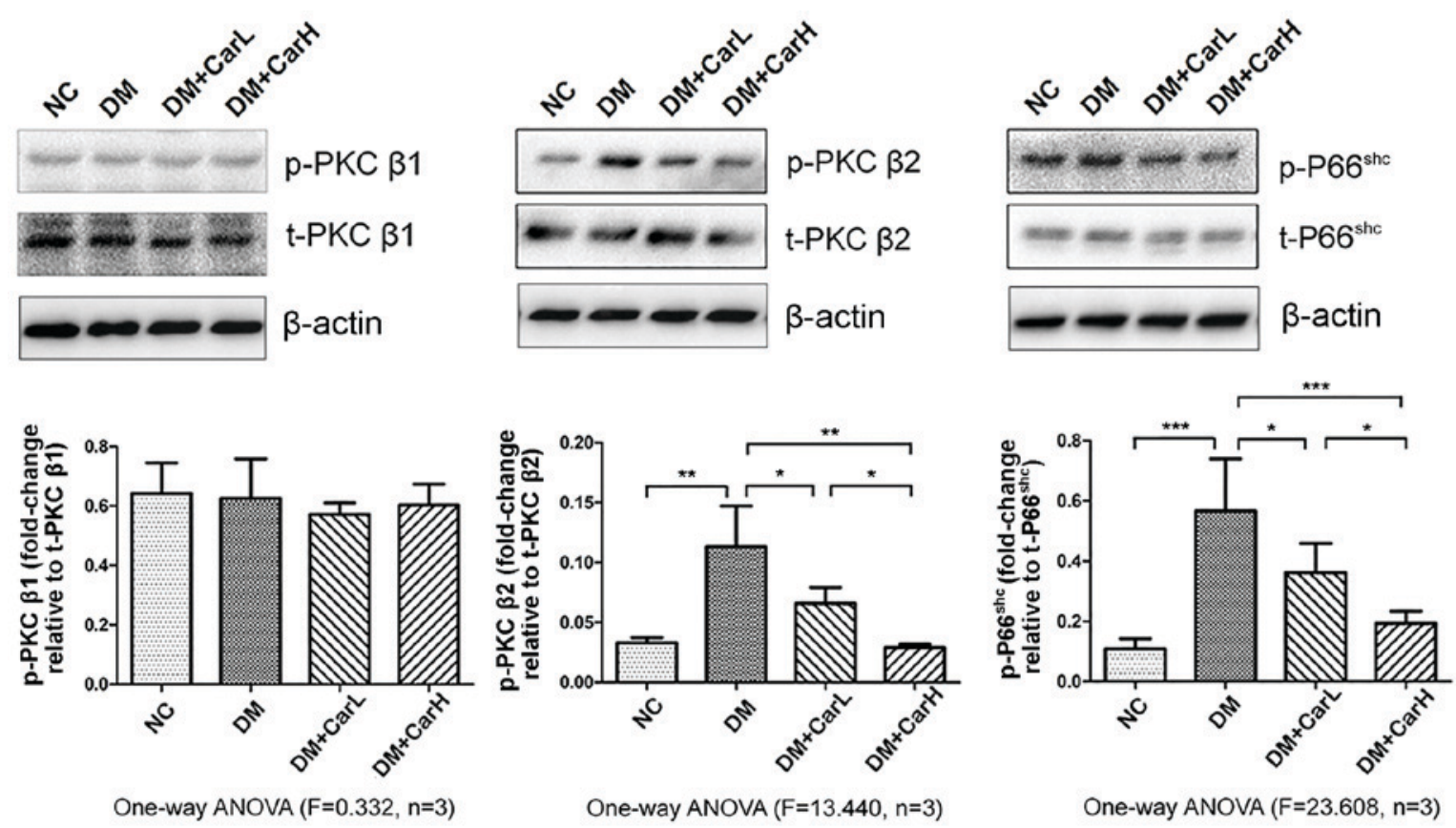

Figure 4. Carvedilol suppressed the PKC $\beta_{2} / \mathrm{P} 66^{\text {shc }}$ signaling pathway. Western blot analysis of $\mathrm{p}-\mathrm{PKC} \beta_{1}, \mathrm{t}-\mathrm{PKC} \beta_{1}, \mathrm{p}-\mathrm{PKC} \beta_{2}, \mathrm{t}-\mathrm{PKC} \beta_{2}, \mathrm{p}-\mathrm{P} 66^{\text {shc }}$ and $\mathrm{t}-\mathrm{P} 66^{\text {shc }}$ in myocardial tissue protein expression. ${ }^{*} \mathrm{P}<0.05,{ }^{* *} \mathrm{P}<0.01$ and ${ }^{* * *} \mathrm{P}<0.01$. PKC, protein kinase C; p, phosphorylated; t, total; NC, normal control; DM, diabetes mellitus; CarL, carvedilol low dosage; CarH, carvedilol high dosage; ANOVA, analysis of variance.

attenuated the development of the aforementioned characteristic alterations in DCM. The present data supported the protective effect of carvedilol against DCM. First, carvedilol treatment alleviated the increase in $\mathrm{HW} / \mathrm{BW}$ ratio and relatively increased body weight; however, had no effect on the levels of blood glucose and cholesterol. Second, carvedilol appeared to protect cardiac function as evaluated by echocardiography and the serum level of NT-proBNP. Third, as is well established, an important hallmark of DCM is fibrosis (28). Morsy et al (29) reported that carvedilol may protect STZ-induced early diabetic nephropathy fibrosis in rats via antioxidant as well as anti-inflammatory activities. The current results demonstrated that carvedilol markedly ameliorated cardiac fibrosis and ultrastructural changes in DCM rats. Fourth, oxidative stress is defined as the imbalance between the production and elimination of oxygen-free radicals, which serve an essential role in the development of heart failure in DCM (30). Hyperglycemia accelerates the glucose oxidation response and mitochondrial generation of ROS, which results in damage of DNA fragments and contributes to exacerbated apoptosis. The activation of $\mathrm{PKC} \beta_{2}$ may serve a crucial role in the occurrence of oxidative stress injury in DCM. Presently, the inhibition of $\mathrm{PKC} \beta_{2}$ activation by carvedilol appeared to attenuate DCM-associated myocardial injury at least partly via reduction of $\mathrm{P} 66^{\text {shc }}$. $\mathrm{P} 66^{\text {shc }}$ is a redox enzyme that is implicated in mitochondrial ROS generation, mitochondrial membrane potential change, and the translation of oxidative signals into apoptosis (31). The in vivo experiments of the current study have demonstrated that excessive $\mathrm{P} 6^{\text {sh }}$ activation is associated with $\mathrm{PKC} \beta_{2}$ activation. To the best of our knowledge, the present study is the first to demonstrate an association between $\mathrm{PKC} \beta_{2}$ and $\mathrm{P} 66^{\text {shc }}$ in DCM.

PKC $\beta_{1}$ and $\beta_{2}$ are two of the classic isoforms (among the $\alpha, \beta$ and $\gamma$-types) of PKC (32). Previous studies have indicated that $\mathrm{PKC} \beta_{2}$ is preferentially overexpressed in the myocardium of patients and animals with diabetes $(33,34)$. In the present study, it was demonstrated that the primary activated isoform of PKC in DCM-related oxidative stress was $\mathrm{PKC} \beta_{2}$, and not PKC $\beta_{1}$. Thus, it is possible that a primary effect of carvedilol in DCM is inhibiting the activation of $\mathrm{PKC} \beta_{2}$. The current study also demonstrated that inhibition of $\mathrm{PKC} \beta_{2}$ activation by carvedilol attenuated the overexpression and phosphorylation of $\mathrm{P} 66^{\text {shc }}$ in DCM. The results also demonstrated that carvedilol inhibited the accumulation of MDA (an indicator of lipid peroxidation) and increased the hyperglycemia-induced downregulation of SOD and CAT (two typical primary ROS scavenging enzymes), which demonstrated that carvedilol could inhibit oxidative stress. Furthermore, the present data demonstrated that the $\mathrm{PKC} \beta_{2} / \mathrm{P} 66^{\text {shc }}$ oxidative stress signaling pathway may be associated with the process of DCM. It was also observed that hyperglycemia-induced myocardial injury markedly increased the serum levels of TNF- $\alpha$ and IL-1 $\beta$ (two typical pro-inflammatory cytokines), which suggested that a severe myocardial inflammation response was induced during the development of DCM. Carvedilol administration inhibited this increase in the serum concentration of TNF- $\alpha$ and IL-1 $\beta$. Finally, in addition to ameliorating cardiac inflammation, carvedilol treatment also appeared to reduce cardiomyocyte apoptosis. Cardiomyocyte apoptosis is an important pathological change that contributes to cardiac dysfunction in DCM (35). Caspase-3, an established pro-apoptotic protease, serves an important role in the formation of apoptotic bodies and induction of cell death. In the untreated DM group, caspase-3 was markedly elevated, while in the carvedilol treatment group, cardiomyocyte caspase- 3 activity and subsequent apoptosis were reduced.

Taken together, the present study results demonstrate that the principal activated isoform of PKC in DCM may be $\mathrm{PKC} \beta_{2}$, 
and not $\mathrm{PKC} \beta_{1}$; furthermore, carvedilol-mediated alleviation of myocardial injury and systemic inflammation in DCM may occur through its inhibition of $\mathrm{P} 66^{\text {shc }}$-mediated oxidative stress and subsequent apoptosis. Considering these present findings, carvedilol may represent a novel, clinically applicable therapy for DCM.

\section{Acknowledgements}

The authors would like to thank The North China University of Science and Technology for technical support during the experiments.

\section{Funding}

The current study was supported by Hebei Province Key Projects of Medical Science Research Grants 2018 (grant no. 20181253).

\section{Availability of data and materials}

All data are available without restriction.

\section{Authors' contributions}

WZ performed the study and wrote the manuscript. WZ and DL contributed to data analysis and interpretation. WZ, DL, XG and WZ contributed materials and analysis tools. BOR reviewed the manuscript.

\section{Ethics approval and consent to participate}

All experimental protocols were approved by the Animal Care and Use Committee of North China University of Science and Technology, and in compliance with Guidelines for the Care and Use of Laboratory Animals Published by the National Academy Press (NIH publication no. 85-23, revised 1996).

\section{Patient consent for publication}

Not applicable.

\section{Competing interests}

The authors declare that they have no competing interests.

\section{References}

1. Shaw JE, Sicree RA and Zimmet PZ: Global estimates of the prevalence of diabetes for 2010 and 2030. Diabetes Res Clin Pract 87: 4-14, 2010.

2. Bell DS: Heart failure: The frequent, forgotten, and often fatal complication of diabetes. Diabetes Care 26: 2433-2441, 2003.

3. Fang ZY, Prins JB and Marwick TH: Diabetic cardiomyopathy: Evidence, mechanisms, and therapeutic implications. Endocr Rev 25: 543-567, 2004.

4. Westermann D, Walther T, Savvatis K, Escher F, Sobirey M, Riad A, Bader M, Schultheiss HP and Tschöpe C: Gene deletion of the kinin receptor B1 attenuates cardiac inflammation and fibrosis during the development of experimental diabetic cardiomyopathy. Diabetes 58: 1373-1381, 2009.

5. Falcão-Pires I and Leite-Moreira AF: Diabetic cardiomyopathy: Understanding the molecular and cellular basis to progress in diagnosis and treatment. Heart Fail Rev 17: 325-344, 2012.
6. Aksakal E, Akaras N, Kurt M, Tanboga IH, Halici Z, Odabasoglu F, Bakirci EM and Unal B: The role of oxidative stress in diabetic cardiomyopathy: An experimental study. Eur Rev Med Pharmacol Sci 15: 1241-1246, 2011.

7. Halliwell B: Biochemistry of oxidative stress. Biochem Soc Trans 35: 1147-1150, 2007.

8. Matés JM and Sánchez-Jiménez F: Antioxidant enzymes and their implications in pathophysiologic processes. Front Biosci 4: D339-D345, 1999.

9. Mellor $\mathrm{H}$ and Parker P: The extended protein kinase $\mathrm{C}$ superfamily. Biochem J 332: 281-292, 1998.

10. Gurusamy N, Watanabe K, Ma M, Zhang S, Muslin AJ, Kodama $M$ and Aizawa $Y$ : Inactivation of 14-3-3 protein exacerbates cardiac hypertrophy and fibrosis through enhanced expression of protein kinase $\mathrm{C}$ beta 2 in experimental diabetes. Biol Pharm Bull 28: 957-962, 2005.

11. Way KJ, Isshiki K, Suzuma K, Yokota T, Zvagelsky D, Schoen FJ, Sandusky GE, Pechous PA, Vlahos CJ, Wakasaki H and King GL: Expression of connective tissue growth factor is increased in injured myocardium associated with protein kinase $\mathrm{C}$ beta2 activation and diabetes. Diabetes 51: 2709-2718, 2002.

12. Migliaccio E, Giorgio M, Mele S, Pelicci G, Reboldi P, Pandolfi PP, Lanfrancone L and Pelicci PG: The p66shc adaptor protein controls oxidative stress response and life span in mammals. Nature 402: 309-313, 1999.

13. Nemoto $\mathrm{S}$ and Finkel T: Redox regulation of forkhead proteins through a p66shc-dependent signaling pathway. Science 295: 2450-2452, 2002.

14. Pinton P, Rimessi A, Marchi S, Orsini F, Migliaccio E, Giorgio M, Contursi C, Minucci S, Mantovani F, Wieckowski MR, et al: Protein kinase $\mathrm{C}$ beta and prolyl isomerase 1 regulate mitochondrial effects of the life-span determinant p66Shc. Science 315: 659-663, 2007.

15. Paneni F, Mocharla P, Akhmedov A, Costantino S, Osto E, Volpe M, Lüscher TF and Cosentino F: Gene silencing of the mitochondrial adaptor p66shc suppresses vascular hyperglycemic memory in diabetes. Circ Res 111: 278-289, 2012.

16. Arab HH and El-Sawalhi MM: Carvedilol alleviates adjuvant-induced arthritis and subcutaneous air pouch edema: Modulation of oxidative stress and inflammatory mediators. Toxicol Appl Pharmacol 268: 241-248, 2013.

17. Yasar A, Erdemir F, Parlaktas BS, Atilgan D, Koseoglu RD, Saylan O and Firat F: The effect of carvedilol on serum and tissue oxidative stress parameters in partial ureteral obstruction induced rat model. Kaohsiung J Med Sci 29: 19-25, 2013.

18. Feuerstein GZ, Poste G and Ruffolo RR Jr: Carvedilol update III: Rationale for and use in congestive heart failure. Drugs Today 31: 307-326, 1995 .

19. National Research Council (US) Committee for the Update of the Guide for the Care and Use of Laboratory Animals: Guide for the care and use of laboratory animals: Eighth edition. Publication no. 85-23(rev.) 327: pp. 963-965, 1996.

20. Maeda H, Nagai H, Takemura G, Shintani-Ishida K, Komatsu M, Ogura S, Aki T, Shirai M, Kuwahira I and Yoshida K: Intermittent-hypoxia induced autophagy attenuates contractile dysfunction and myocardial injury in rat heart. Biochim Biophys Acta 1832: 1159-1166, 2013.

21. Frustaci A, Kajstura J, Chimenti C, Jakoniuk I, Leri A, Maseri A, Nadal-Ginard B and Anversa P: Myocardial cell death in human diabetes. Circ Res 87: 1123-1132, 2000.

22. Liu X, Li B, Wang W, Zhang C, Zhang M, Zhang Y, Xia Y, Dong Z, Guo Y and An F: Effects of HMG-CoA reductase inhibitor on experimental autoimmune myocarditis. Cardiovase Drugs Ther 26: 121-130, 2012.

23. Lei S, Li H, Xu J, Liu Y, Gao X, Wang J, Ng KF, Lau WB, Ma XL, Rodrigues $\mathrm{B}$, et al: Hyperglycemia-induced protein kinase $\mathrm{C} \beta 2$ activation induces diastolic cardiac dysfunction in diabetic rats by impairing caveolin-3 expression and Akt/eNOS signaling. Diabetes 62: 2318-2328, 2013.

24. Huang H, Shan J, Pan XH, Wang HP and Qian LB: Carvedilol protected diabetic rat hearts via reducing oxidative stress. J Zhejiang Univ Sci B 7: 725-731, 2006.

25. Olsen SL, Gilbert EM, Renlund DG, Taylor DO, Yanowitz FD and Bristow MR: Carvedilol improves left ventricular function and symptoms in chronic heart failure: A double-blind randomized study. J Am Coll Cardiol 25: 1225-1231, 1995.

26. Packer M, Bristow MR, Cohn JN, Colucci WS, Fowler MB, Gilbert EM and Shusterman NH: The effect of carvedilol on morbidity and mortality in patients with chronic heart failure. N Engl J Med 334: 1349-1355, 1996. 
27. Tarquini R, Lazzeri C, Pala L, Rotella CM and Gensini GF: The diabetic cardiomyopathy. Acta Diabetol 48: 173-181, 2011.

28. Zhou H, Li YJ, Wang M, Zhang LH, Guo BY, Zhao ZS, Meng FL, Deng YG and Wang RY: Involvement of RhoA/ROCK in myocardial fibrosis in a rat model of type 2 diabetes. Acta Pharmacol Sin 32: 999-1008, 2011.

29. Morsy MA, Ibrahim SA, Amin EF, Kamel MY, Abdelwahab SA and Hassan MK: Carvedilol ameliorates early diabetic nephropathy in streptozotocin-induced diabetic rats. Biomed Res Int 2014: 105214, 2014.

30. Rajesh M, Mukhopadhyay P, Bátkai S, Patel V, Saito K, Matsumoto S, Kashiwaya Y, Horváth B, Mukhopadhyay B, Becker L, et al: Cannabidiol attenuates cardiac dysfunction, oxidative stress, fibrosis, and inflammatory and cell death signaling pathways in diabetic cardiomyopathy. J Am Coll Cardiol 56: 2115-2125, 2010.

31. Chen Z, Wang G, Zhai X, Hu Y, Gao D, Ma L, Yao J and Tian X: Selective inhibition of protein kinase $C \beta 2$ attenuates the adaptor P66Shc-mediated intestinal ischemia-reperfusion injury. Cell Death Dis 5: e1164, 2014
32. Clarke $\mathrm{M}$ and Dodson PM: PKC inhibition and diabetic microvascular complications. Best Pract Res Clin Endocrinol Metab 21: 573-586, 2007

33. Simpson PC: Beta-protein kinase $\mathrm{C}$ and hypertrophic signaling in human heart failure. Circulation 99: 334-337, 1999.

34. Connelly KA, Kelly DJ, Zhang Y, Prior DL, Advani A, Cox AJ, Thai K, Krum $\mathrm{H}$ and Gilbert RE: Inhibition of protein kinase C-beta by ruboxistaurin preserves cardiac function and reduces extracellular matrix production in diabetic cardiomyopathy. Circ Heart Fail 2: 129-137, 2009.

35. Devereux RB, Roman MJ, Paranicas M, O'Grady MJ, Lee ET, Welty TK, Fabsitz RR, Robbins D, Rhoades ER and Howard BV: Impact of diabetes on cardiac structure and function the strong heart study. Circulation 101: 2271-2276, 2000. 